\title{
A Coordination Contract for Green Agricultural Product Supply Chain with Stochastic Output
}

\author{
Chongfeng $\operatorname{Lan}^{1,2}$ \\ ${ }^{1}$ School of Economics, Fuyang Normal University, Fuyang 236037, China \\ ${ }^{2}$ Anhui Provincial Key Laboratory of Regional Logistics Planning and Modern Logistics Engineering, Fuyang 236037, China
}

Corresponding Author Email: 200307016@fynu.edu.cn

https://doi.org/10.18280/jesa.520403

Received: 28 March 2019

Accepted: 10 July 2019

\section{Keywords:}

green supply chain (SC), two-part tariff

(TPT) contract, stochastic output,

coordination

\begin{abstract}
Considering the stochasticity in the output of agricultural products (APs), this paper establishes a green supply chain (SC) model of "cooperative + supermarket" based on Stackelberg game. Then, the optimal strategies of the producer and the seller were obtained under the decentralized and centralized decision-making models, respectively. Finally, an example analysis was conducted to analyze the sensitivity of consumer's greenness sensitivity, green cost coefficient and stochastic output ratio. The results show that: the green SC with stochastic demand cannot be coordinated under the decentralized model; the two-part traffic (TPT) contract causes the producer and the seller to fully cooperate with each other, which improves the AP greenness, optimizes the SC environment, increases the producer's expected profit and coordinates the entire SC; however, the seller's expected profit under the TPT contract will be the same as that under the decentralized model.
\end{abstract}

\section{INTRODUCTION}

In recent years, many unsafe foods came to light in China, including cucumbers containing female hormones, pork tainted with clenbuterol, steamed buns polluted by sulfur. The numerous food safety incidents are disturbing to Chinese consumers, raising their awareness of green consumption and environmental protection. In October, 2015, the Chinese authority, for the very first time, defined that green development as the sustainable development following the laws of nature and the fundamental way to realize ecological civilization. Recently, sustainable supply chain (SC)has become an extensively researched measure to cope with laws and regulations, consumer demand, intratype competition and social responsibility [1]. The core of sustainable SC management lies in ecological issues, such as design and production of green products, the manufacturing of byproducts, the generation of by-production in the use of primary products, and the reverse logistics [2].

The quality and safety of agricultural products (APs) are the vital interests of all consumers. Under the national strategy of "green, low-carbon and circular development", the development of green APs marks the future of modern agriculture and gives a strong impetus to the sustainable growth of China's economy. Therefore, it is imperative to construct and optimize an SC model of green APs [3].

Currently, the safe APs in China mainly fall into organic APs, nuisance-free APs and green APs. Among them, green APs have been the research focus of modern APs, because organic APs are expensive and short-supplied, and nuisancefree ones are not well recognized in the market [4].

Many Chinese and foreign scholars have probed deep into the management of green SC [5-8], but few have explored how to manage green AP SC. Sarkis [9] was the first to identify the management elements of green AP SC, laying the basis for the decision-making framework. Burer et al. [10] analyzed different types of contracts used in the seed industry, and summed up the features of all coordination contracts, assuming that the demand is uniformly distributed. Liu et al. [11] systematically discussed how to transform the green AP SC into a closed-loop SC. To curb the huge loss of fresh APs in circulation, Wang et al. [12] optimized the option and order quantity of the retailer, as well as the pricing strategy of the supplier, using the option contract. Ge et al. [13] investigated the complex internal optimization problems of agricultural SC, and developed an effective solution through simulation. Chen [14] studied the game between the parties in the green AP SC, and constructed the game model between three parties, namely, the government, the enterprise and the consumer, revealing that the optimal outcome is achieved when the government does not monitor the enterprise behavior concerning the green AP SC. Considering the features (e.g. freshness and loss) of APs, Yang and Lu [15] set up a stochastic profit distribution model, and proposed a coordination strategy for three-echelon SC based on transaction credit. With the aid of the theory of variational inequality, Zhou et al. [16] investigated the equilibrium of fresh AP SC under the consumer preference for organic products, and concluded that both the producer and retailer make more profits with the growth in consumer preference for organic products. However, none of the above studies have considered the uncertainty of AP output.

Unlike processing and manufacturing industries, the production and sales of APs are susceptible to uncertainties like weather and seasonal changes. There is often a certain stochasticity in AP output. Thus, the exploration of the AP SC with stochastic output has many realistic benefits, such as guiding AP producers and sellers in operation and management [17]. Zhao and $\mathrm{Wu}$ [18] used the profit-sharing contract to coordinate the secondary AP SC under stochastic output and demand. Kazaz and Webster [19] discussed the optimal production decisions of agro-industrialization organizations, whose stochastic output affects the AP price. 
Assuming that the supplier makes a constant capital investment in agriculture and that the output is stochastic, Zhao et al. [20] suggested that the supplier and retailer should bear the risks of stochastic output together through shortsupply and over-supply compensations. Under stochastic output and demand, Feng et al. [21] coordinated the AP SC weakly dominated by third-party logistics (TPL) service provider. Considering stochastic AP output and government compensation of prepayment loss, Huang et al. [22] constructed an AP SC game model based on transaction credit, and discussed low government compensation contributes to social welfare and SC value. Despite tackling stochastic AP output, the above studies fail to consider the effects of AP greenness on optimal SC decisions.

The cooperation between SC parties plays an increasingly important role in the management of sustainable SCs. The SC environment can be improved through the coordination of the green SC [7]. Therefore, this paper mainly deals with the coordination of green AP SC. Considering stochasticity of AP output, the author built a green SC model of "cooperative + supermarket" upon game theory. The optimal strategies of the producer and seller under decentralized decision-making model were compared with those under centralized decisionmaking model. On this basis, the two-part tariff (TPT) contract was introduced to coordinate green AP SC.

There are two major innovations of our research: (1) Both stochastic output and greenness were included in the decisionmaking process of the $\mathrm{AP} \mathrm{SC}$, and their impacts on $\mathrm{SC}$ operations were discussed; (2) The proposed TPT coordination mechanism not only optimizes the expected profit of the SC, but also improves the SC environment, shedding new lights on the decision-making of relevant enterprises.

\section{PROBLEM DESCRIPTION AND HYPOTHESES}

Our problem involves a secondary green SC consisting of a supermarket and a rural cooperative. The supermarket sells the green APs produced by the rural cooperative. The seller and the producer are engaged in a Stackelberg game under symmetric information. The producer is the first mover in the game. Before the sales season, the producer first determines the greenness $\theta$ and wholesale price $w$ of APs. Then, the seller decides on the order quantity $q$ of APs based on the producer's decision and predicted market demand. For convenience, several hypotheses were put forward before modelling and analysis.

Hypothesis 1. The AP output is stochastic under the effects of uncontrollable factors, such as plant diseases, insect pests, extreme weather, abnormal temperature and any other natural disaster. In this paper, the producer's output stochasticity is described by the commonly used stochastic output ratio model $[23,24]$ : the seller's AP order quantity and the producer's actual output are denoted as $q$ and $\varepsilon q$, respectively; $\varepsilon \in[0,1]$ is the stochastic output ratio of green APs that obeys a distribution-free model (mean $\mu$; variance $\sigma^{2}$ ) [25]. Facing the risks of stochastic output, the seller can only sell the actual output in the retail market.

Hypothesis 2. Boyabatli et al. [26] proved the negative linear correlation between AP price and output. Hence, it is assumed that $p(q)=a-b \varepsilon q$, where $a>0$ is the "choke" price (the price so high that there is no demand for the AP), $b>0$ is the consumer's sensitivity to price, $\varepsilon q$ is the AP output, order quantity and also sales volume in the current season. It is also assumed that there is no residual AP at the end of the season. Drawing on the research of Liu et al. [27], the AP price has a positive linear correlation with its greenness Thus, the inverse demand of green AP market could be defined as $p(q, \theta)=a-b \varepsilon q+\lambda \theta$, where $0 \leq \theta<1$ is AP greenness, i.e. the edge of green APs over traditional APs in emissions reduction, and $\lambda>0$ is the consumer's greenness sensitivity, i.e. the consumer's awareness of environmental protection (the consumer is willing to pay a higher price for greener APs).

Hypothesis 3. The production cost of the cooperative can be broken down into two parts: the marginal cost of AP production and the green cost (the fixed investment to improve AP greenness, mainly incurred in the application of green fertilizers and the R\&D of green technologies). According to the findings of Agbo et al. [28], the AP production cost $C(q)$ is an increasing convex function of the capital investment in agriculture in the current season and satisfies $C(0)=0$. Therefore, the marginal cost of AP production was assumed as $C(q)=\frac{1}{2} \alpha q^{2}$, where $\alpha>0$ is the AP production coefficient. Meanwhile, the green $\operatorname{cost} H(\theta)$ is correlated with AP greenness $\theta$, and satisfies $H^{\prime}(\theta)>0$ and $H^{\prime \prime}(\theta)>0$. Using an existing green product investment model [7], the author illustrated the green cost as a quadratic function: $H(\theta)=$ $\frac{1}{2} \beta \theta^{2}$, where $\beta>0$ is the green cost coefficient. In this paper, the green cost refers specifically to the one-time up-front input by the producer. In other words, the green cost coefficient $\beta$ is usually large enough [7].

For simplicity, the parameters of the seller, the producer and the SC were respectively marked with the superscripts $s, m$ and $m s$. The parameters under the decentralized, centralized and coordinated decision-making models were respectively marked with subscripts $d, c$ and $c o$, respectively.

\section{DECISION-MAKING MODELS}

\subsection{Decentralized decision-making model}

According to the problem descriptions and hypotheses, the seller profit and producer profit under decentralized decisionmaking model can be respectively described as:

$$
\begin{gathered}
\pi_{d}^{s}(q)=p(q, \theta) \varepsilon q-w \varepsilon q=\varepsilon q(a-b \varepsilon q+\lambda \theta-w) \\
\pi_{d}^{m}(w, \theta)=w \varepsilon q-C(q)-H(\theta)=w \varepsilon q-\frac{1}{2} \alpha q^{2}-\frac{1}{2} \beta \theta^{2}
\end{gathered}
$$

By formulas (1) and (2), the expected profits of the seller and the producer can be respectively obtained as:

$$
\begin{gathered}
E\left[\pi_{d}^{s}(q)\right]=(a+\lambda \theta-w) \mu q-b\left(\mu^{2}+\sigma^{2}\right) q^{2} \\
E\left[\pi_{d}^{m}(w, \theta)\right]=w \mu q-\frac{1}{2} \alpha q^{2}-\frac{1}{2} \beta \theta^{2}
\end{gathered}
$$

In the Stackelbergy game, both the seller and the producer pursue the maximum profit. Then, the equilibrium solution of the decentralized decision-making model was deduced inversely.

In phase 2 , the seller decides on the optimal order quantity of APs. According to formula (3), the first-order condition of $E\left[\pi_{d}^{s}(q)\right]$ relative to $q$ can be derived as: 


$$
\frac{d E\left[\pi_{d}^{S}(q)\right]}{d q}=(a+\lambda \theta-w) \mu-2 b\left(\mu^{2}+\sigma^{2}\right) q=0
$$

Since $\frac{d^{2} E\left[\pi_{d}^{S}(q)\right]}{d q^{2}}=-2 b\left(\mu^{2}+\sigma^{2}\right)<0, E\left[\pi_{d}^{S}(q)\right]$ is a concave function about $q$. Let $A=\frac{\mu}{2 b\left(\mu^{2}+\sigma^{2}\right)}$. Then, the unique optimal response $q_{d}^{*}$ of the seller must be:

$$
q_{d}^{*}=A(a+\lambda \theta-w)
$$

In phase 1 , the producer determines the optimal wholesale price and greenness of APs. Substituting formula (6) into formula (4), the Hessian matrix $H(w, \theta)$ of $E\left[\pi_{d}^{m}(w, \theta)\right]$ about $(w, \theta)$ can be established as:

$$
\begin{gathered}
H(w, \theta)=\left[\begin{array}{ll}
\frac{\partial^{2} E\left[\pi_{d}^{m}(w, \theta)\right]}{\partial w^{2}} & \frac{\partial^{2} E\left[\pi_{d}^{m}(w, \theta)\right]}{\partial w \partial \theta} \\
\frac{\partial^{2} E\left[\pi_{d}^{m}(w, \theta)\right]}{\partial \theta \partial w} & \frac{\partial^{2} E\left[\pi_{d}^{m}(w, \theta)\right]}{\partial \theta^{2}}
\end{array}\right]= \\
{\left[\begin{array}{ll}
-A^{2} \alpha-2 A \mu & A^{2} \alpha \lambda+A \lambda \mu \\
A^{2} \alpha \lambda+A \lambda \mu & -\beta-A^{2} \alpha \lambda^{2}
\end{array}\right]}
\end{gathered}
$$

The first-order leading principal minors $D_{1}=\frac{\partial^{2} \pi_{m}(w, \theta)}{\partial w^{2}}=$ $-A^{2} \alpha-2 A \mu<0$. Since the green cost coefficient $\beta$ is large enough, the second-order leading principal minors $D_{2}=$ $A\left(A \alpha \beta+2 \beta \mu-A \lambda^{2} \mu^{2}\right)>0$. Therefore, $H(w, \theta)$ is a negative definite matrix. Then, $E\left[\pi_{d}^{m}(w, \theta)\right]$ must be a joint concave function about $(w, \theta)$. The unique optimal response of the producer to the order quantity of green APs $\left(w_{d}^{*}, \theta_{d}^{*}\right)$ can be determined by:

$$
\left\{\begin{array}{c}
\frac{\partial E\left[\pi_{d}^{m}(w, \theta)\right]}{\partial w}=A^{2} \alpha(a-w+\theta \lambda)-A w \mu+A(a-w+\theta \lambda) \mu=0 \\
\frac{\partial E\left[\pi_{d}^{m}(w, \theta)\right]}{\partial \theta}=-\beta \theta-A^{2} \alpha \lambda(a-w+\theta \lambda)+A w \lambda \mu=0
\end{array}\right.
$$

Solve equation set (8), we have:

$$
\left\{\begin{array}{l}
w_{d}^{*}=\frac{A a \alpha \beta+a \beta \mu}{A \alpha \beta+2 \beta \mu-A \lambda^{2} \mu^{2}} \\
\theta_{d}^{*}=\frac{A a \lambda \mu^{2}}{A \alpha \beta+2 \beta \mu-A \lambda^{2} \mu^{2}}
\end{array}\right.
$$

Substituting the values of $w_{d}^{*}$ and $\theta_{d}^{*}$ into formula (6), the following conclusion can be drawn:

Theorem 1. Under decentralized decision-making, the equilibrium outcome of the Stackelberg game between the seller and the producer is:

$$
\left\{\begin{aligned}
w_{d}^{*} & =\frac{A a \alpha \beta+a \beta \mu}{A \alpha \beta+2 \beta \mu-A \lambda^{2} \mu^{2}} \\
\theta_{d}^{*} & =\frac{A a \lambda \mu^{2}}{A \alpha \beta+2 \beta \mu-A \lambda^{2} \mu^{2}} \\
q_{d}^{*} & =\frac{A a \beta \mu}{A \alpha \beta+2 \beta \mu-A \lambda^{2} \mu^{2}}
\end{aligned}\right.
$$

Property 1 can be derived from how SC parties are affected by green cost coefficient and consumer's greenness sensitivity.

Property 1. Under decentralized decision-making, the following inequalities are valid under the existence of the optimal solution:

$$
\begin{aligned}
& \text { 1) } \left.\frac{\partial w_{d}^{*}}{\partial \lambda}>0, \frac{\partial \theta_{d}^{*}}{\partial \lambda}>0 \text { and } \frac{\partial q_{d}^{*}}{\partial \lambda}>0 ; 2\right) \frac{\partial w_{d}^{*}}{\partial \beta}<0, \frac{\partial \theta_{d}^{*}}{\partial \beta}<0 \text { and } \\
& \frac{\partial q_{d}^{*}}{\partial \beta}<0 .
\end{aligned}
$$

Proof: Property 1 can be proved by finding the partial derivatives of $w_{d}^{*}, \theta_{d}^{*}$ and $q_{d}^{*}$ relative to $\lambda$ and $\beta$, respectively.

Property 1 shows that, if the consumer has a high awareness of environmental protection, he/she will be sensitive to AP greenness and willing to pay an extra fee for green APs. In this case, the seller will benefit from the high product demand, while the producer will benefit from the high price and invest more to improve product greenness. If it is costly to develop green technologies, the profit of improving product greenness cannot make up for the technical R\&D cost. To save cost, the producer will lower the AP greenness and wholesale price, while the seller will cut back on the AP order quantity.

Substituting the equilibrium solution (10) into the objective functions (3) and (4), the seller profit, producer profit and SC profit can be respectively obtained as:

$$
\left\{\begin{array}{c}
E\left(\pi_{d}^{s *}\right)=\frac{a^{2} A \beta^{2} \mu^{3}}{2\left(A \alpha \beta+2 \beta \mu-A \lambda^{2} \mu^{2}\right)^{2}} \\
E\left(\pi_{d}^{m *}\right)=\frac{a^{2} A \beta \mu^{2}}{2 A \alpha \beta+4 \beta \mu-2 A \lambda^{2} \mu^{2}} \\
E\left(\pi_{d}^{m s^{*}}\right)=\frac{a^{2} A \beta \mu^{2}\left(A \alpha \beta+3 \beta \mu-A \lambda^{2} \mu^{2}\right)}{2\left(A \alpha \beta+2 \beta \mu-A \lambda^{2} \mu^{2}\right)^{2}}
\end{array}\right.
$$

\subsection{Centralized decision-making model}

Under centralized decision-making, the seller fully cooperates with the producer. In this case, the decision-making is only affected by the order quantity and green cost, and has nothing to do with wholesale price. Then, the decision-making of the SC can be described as:

$$
\begin{gathered}
\max _{\theta_{c}, q_{c}} E\left[\pi_{c}\left(\theta_{c}, q_{c}\right)\right]= \\
\left(a+\lambda \theta_{c}\right) \mu q_{c}-\left[\frac{1}{2} \alpha+b\left(\mu^{2}+\sigma^{2}\right)\right] q_{c}^{2}-\frac{1}{2} \beta \theta_{c}^{2}
\end{gathered}
$$

Theorem 2. Under centralized decision-making, the optimal decisions of the SC include:

$$
\left\{\begin{array}{l}
\theta_{c}^{*}=\frac{A a \lambda \mu^{2}}{A \alpha \beta+\beta \mu-A \lambda^{2} \mu^{2}} \\
q_{c}^{*}=\frac{A a \beta \mu}{A \alpha \beta+\beta \mu-A \lambda^{2} \mu^{2}}
\end{array}\right.
$$

Substituting formula (13) into objective function (12), the maximum profit of the $\mathrm{SC}$ can be described as:

$$
E\left(\pi_{c}^{*}\right)=\frac{a^{2} A \beta \mu^{2}}{2 A \alpha \beta+2 \beta \mu-2 A \lambda^{2} \mu^{2}}
$$

Comparing formulas (10) and (13), it is easy to find that $A \alpha \beta+2 \beta \mu-A \lambda^{2} \mu^{2}>A \alpha \beta+\beta \mu-A \lambda^{2} \mu^{2}$. Then, Property 2 can be established.

Property 2. $\theta_{c}^{*}>\theta_{d}^{*}$ and $q_{c}^{*}>q_{d}^{*}$.

Property 2 shows that, compared with decentralized decision-making, centralized decision-making model boasts high AP greenness and a large order quantity. This means the green AP SC cannot be coordinated under decentralized decision-making, and the environment could be improved if the two parties of the SC fully cooperates in taking environmental responsibilities.

\subsection{SC coordination model}

According to Property 2, the SC cannot be coordinated under decentralized decision-making, because the two parties 
emphasize their own profits over the SC profit; the optimal decisions of the two parties are inferior to those under centralized decision-making. To encourage the seller order more green APs and thus coordinate the $\mathrm{SC}$, this paper coordinates the SC with the TPT contract $\left\{w_{c o}, T\right\}$, which is widely used to manage green SCs. Note that $w_{c o}$ is the wholesale price of green APs set by the producer, and $T$ is the fixed transfer payment from the seller to the producer. Let $\theta_{c o}$ be the AP greenness selected by the producer. Similar to Section 3.1, the decision-making of the seller can be expressed as:

$$
\begin{gathered}
\max _{q_{c o}} E\left[\pi_{c o}^{s}\left(q_{c o}\right)\right]= \\
\left(a+\lambda \theta_{c o}-w_{c o}\right) \mu q_{c o}-b\left(\mu^{2}+\sigma^{2}\right) q_{c o}^{2}-T
\end{gathered}
$$

Since $T$ is a fixed transfer payment, the seller's response to the contract terms and AP greenness determined by the producer can be described as:

$$
q_{c o}^{*}=A\left(a+\lambda \theta_{c o}-w_{c o}\right)
$$

Facing the seller's response, the producer's decisionmaking can be expressed as:

$$
\begin{gathered}
\max _{w_{c o}, T, \theta_{c o}} E\left[\pi_{c o}^{m}\left(w_{c o}, T, \theta_{c o}\right)\right]= \\
w_{c o} \mu q_{c o}-\frac{1}{2} \alpha q_{c o}{ }^{2}-\frac{1}{2} \beta \theta_{c o}{ }^{2}+T
\end{gathered}
$$

$$
\text { s.t. }
$$$$
\left(a+\lambda \theta_{c o}-w_{c o}\right) \mu q_{c o}-b\left(\mu^{2}+\sigma^{2}\right) q_{c o}^{2}-T \geq E\left(\pi_{d}^{s *}\right)
$$

Formula (18) is an incentive constraint, ensuring that the seller accepts the coordination contract provided by the producer. The producer's optimal decision can be derived from Theorem 3 below.

Theorem 3. The producer can coordinate the SC by setting the AP greenness as $\theta_{c o}^{*}=\theta_{c}^{*}$ and offers the seller the TPT contract $\left\{w_{c o}^{*}, T^{*}\right\}$ below:

$$
\begin{gathered}
\left\{w_{c o}^{*}, T^{*}\right\}=\left\{a+\frac{A a \lambda^{2} \mu^{2}-a \beta \mu}{A \alpha \beta+\beta \mu-A \lambda^{2} \mu^{2}}, \frac{a^{2} A \beta^{2} \mu^{3}}{2\left(A \alpha \beta+\beta \mu-A \lambda^{2} \mu^{2}\right)^{2}}-\right. \\
\left.\frac{a^{2} A \beta^{2} \mu^{3}}{2\left(A \alpha \beta+2 \beta \mu-A \lambda^{2} \mu^{2}\right)^{2}}\right\} .
\end{gathered}
$$

Proof: For the producer's decision-making in formula (17), the optimal solution must fall on the boundary of Constraint (18). This is a typical moral hazard problem, that is, the producer can take away the entire profit of the seller by manipulating the fixed transfer payment $T$. Hence, if $T=$ $\left(a+\lambda \theta_{c o}-w_{c o}\right) \mu q_{c o}^{*}-b\left(\mu^{2}+\sigma^{2}\right) q_{c o}^{*}{ }^{2}-E\left(\pi_{d}^{s^{*}}\right)$, the producer will face the following decision-making problem:

$$
\begin{aligned}
& \max _{w_{c o}, \theta_{c o}} E\left[\pi_{c o}^{m}\left(w_{c o}, \theta_{c o}\right)\right]=\left(a+\lambda \theta_{c o}\right) \mu q_{c o}^{*}- \\
& {\left[\frac{1}{2} \alpha+b\left(\mu^{2}+\sigma^{2}\right)\right] q_{c o}^{*}{ }^{2}-\frac{1}{2} \beta \theta_{c o}{ }^{2}-E\left(\pi_{d}^{s *}\right)}
\end{aligned}
$$

According to the first-order condition of formula (19) and formula (16), the producer's optimal decision cannot be consistent with the optimal decision of the SC under centralized decision-making, unless $\theta_{c o}^{*}$ and $w_{c o}^{*}$ satisfy:

$$
\left\{\begin{array}{c}
w_{c o}^{*}=a+\frac{A a \lambda^{2} \mu^{2}-a \beta \mu}{A \alpha \beta+\beta \mu-A \lambda^{2} \mu^{2}} \\
\theta_{c o}^{*}=\frac{A a \lambda \mu^{2}}{A \alpha \beta+\beta \mu-A \lambda^{2} \mu^{2}}
\end{array}\right.
$$

Substituting formula (20) into formula (16), we have $q_{c o}^{*}=$ $\frac{A a \beta \mu}{A \alpha \beta+\beta \mu-A \lambda^{2} \mu^{2}}$. Then, we have:

$$
T^{*}=\frac{a^{2} A \beta^{2} \mu^{3}}{2\left(A \alpha \beta+\beta \mu-A \lambda^{2} \mu^{2}\right)^{2}}-\frac{a^{2} A \beta^{2} \mu^{3}}{2\left(A \alpha \beta+2 \beta \mu-A \lambda^{2} \mu^{2}\right)^{2}} .
$$

Property 3. The expected profits of the producer and the seller under decentralized decision-making have the following relationship with those under the coordination contract:

1) $E\left(\pi_{d}^{m *}\right)<E\left(\pi_{c o}^{m *}\right)$; 2) $E\left(\pi_{d}^{S *}\right)=E\left(\pi_{c o}^{S *}\right)$.

Property 3 basically compares the expected profits the producer and the seller under decentralized decision-making and those under the TPT contract: As a leader in the Stackelberg game, the producer has a strong bargaining power and can benefit from a coordinated SC, i.e. $\left(\pi_{c o}^{m *}\right)>E\left(\pi_{d}^{m *}\right)$; on the contrary, the seller, as the follower of the Stackelberg game, has a weak bargaining power, and can receive the same expected profit under decentralized decision-making at the most, i.e. $E\left(\pi_{d}^{s *}\right)=E\left(\pi_{c o}^{s *}\right)$, through SC coordination.

Property 4. If $\Delta \theta_{c o d}=\theta_{c o}^{*}-\theta_{d}^{*}$, then $\frac{\partial \Delta \theta_{c o d}}{\partial \lambda}>0$ and $\frac{\partial \Delta \theta_{\text {cod }}}{\partial \beta}<0$.

Property 4 describes how the AP greenness varies with the changes in consumer's environmental awareness and the R\&D cost coefficient of green technologies: the higher the consumer's environmental awareness, the greater the advantage of the TPT contract in the provision of green APs; the higher the R\&D cost coefficient of green technologies, the fewer the advantage of the TPT contract.

\section{EXAMPLE ANALYSIS}

The example analysis was performed on Matlab under the parameter settings of $a=100, b=1, \mu=0.8, \sigma=0.5, a=15, \beta=50$ and $\lambda=5$. Through the analysis, the decentralized decisionmaking model and the TPT contract model were compared in terms of green sensitivity, green cost coefficient, and the mean and variance of stochastic output. Then, the optimal decisions and expected profits of the green SC and its parties in each model were discussed in details, with the variation in each of the above parameters.

\subsection{Effects of greenness sensitivity}

Firstly, the consumer's greenness sensitivity was subjected to sensitivity analysis, aiming to disclose how this coefficient affects the optimal decisions and expected profits of the green $\mathrm{SC}$ and its parties under decentralized decision-making and under the TPT contract. The relevant numerical experiments were conducted with $\lambda$ as the variable.

As shown in Figure 1, with the increase in consumer's greenness sensitivity, the SC parties both witnessed a rise in optimal decision and expected profit, whether under decentralized decision-making or under the TPT contract. Therefore, the growing environmental awareness of the consumer can encourage the producer to output greener APs and raise the wholesale price, and promote the seller to upscale the order quantity of green APs, thereby benefiting the entire $\mathrm{SC}$.

Comparatively, the producer's green $\cos t \theta^{*}$ is the only parameter that increased marked with the growing $\lambda$, while the other decision variables and expected profits were not 
significantly changed. This means the environment can be greatly improved if the consumer has a high environmental
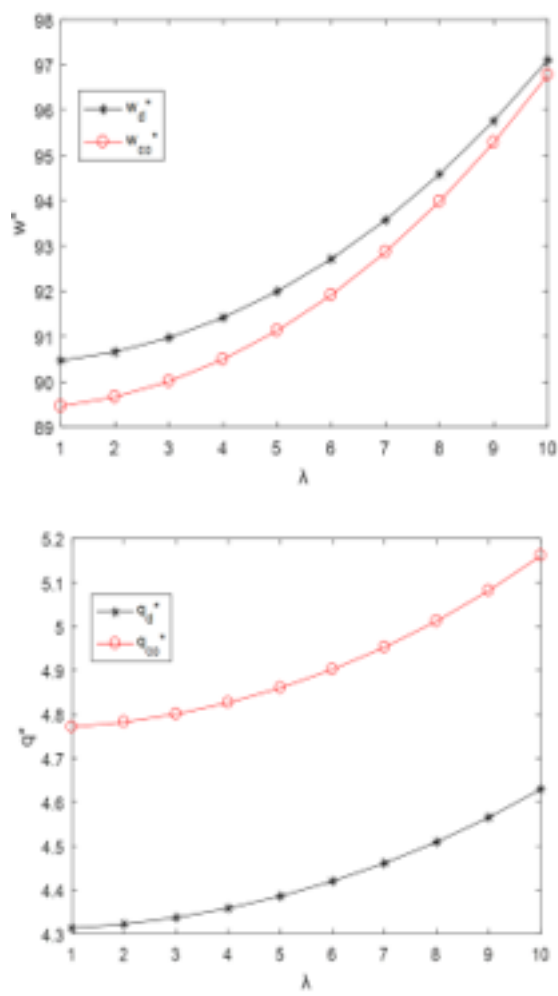

awareness. Thus, we should conduct green marketing to boost the consumer's awareness of environmental protection.
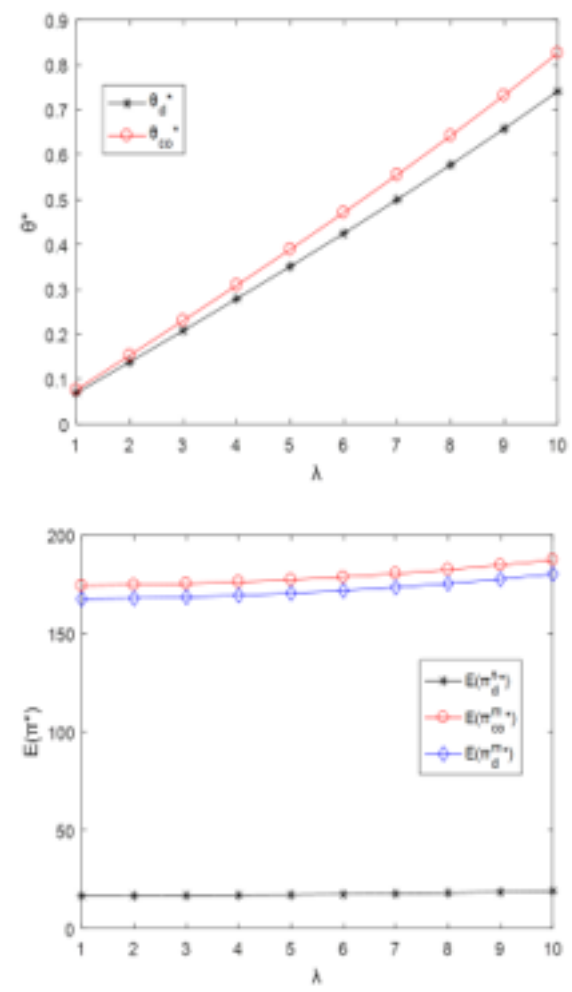

Figure 1. Effects of $\lambda$ on the optimal decisions and expected profits of the green SC and its parties

\subsection{Effects of green cost coefficient}

Secondly, the green cost coefficient was subjected to sensitivity analysis, aiming to disclose how this coefficient
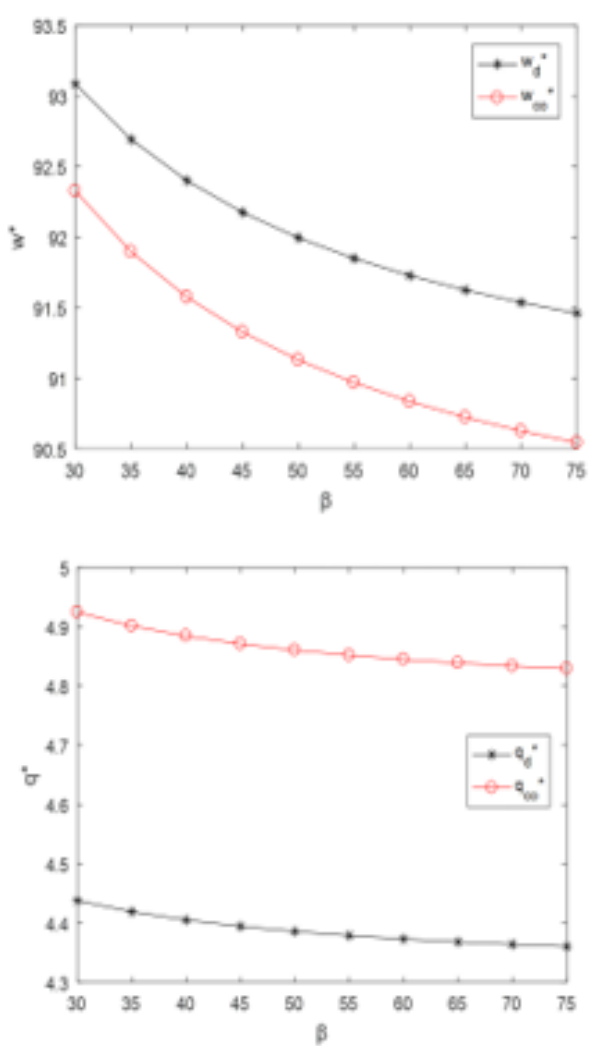

affects the optimal decisions and expected profits of the green $\mathrm{SC}$ and its parties under decentralized decision-making and under the TPT contract. The relevant numerical experiments were conducted with $\beta$ as the variable.
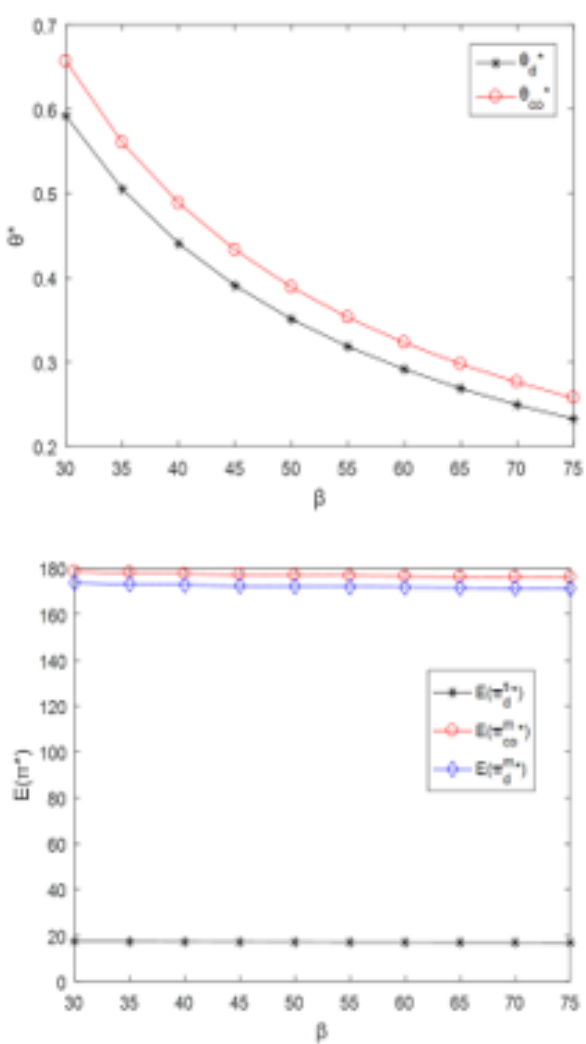

Figure 2. Effects of $\beta$ on the optimal decisions and expected profits of the green SC and its parties 
As shown in Figure 2, with the increase in producer's green cost coefficient, the SC parties both witnessed a decline in optimal decision and expected profit, whether under decentralized decision-making or under the TPT contract. Therefore, under a high R\&D cost of green technologies, the profit of improving product greenness cannot make up for the technical R\&D cost.

To save cost, a rational producer will lower the AP greenness and wholesale price. Then, the market demand will decrease with the greenness, forcing the seller to cut back on the AP order quantity. In this way, the expected profit of the $\mathrm{SC}$ will also decrease.

Comparatively, the producer's green $\cos t \theta^{*}$ is the only parameter that increased marked with the growing $\beta$, while the
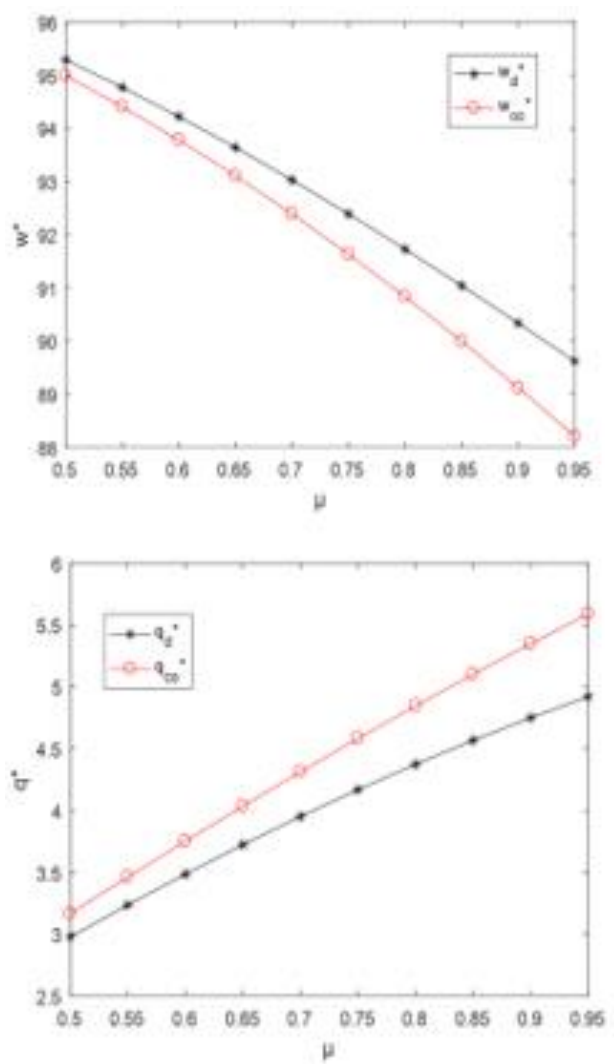

other decision variables and expected profits were not significantly changed. This means a high green cost coefficient is unfavorable to the environment. As a result, we should invest more in green technologies and reduce the R\&D cost of green APs.

\subsection{Effects of the mean of stochastic output ratio}

Thirdly, the author investigated the effects of the mean of stochastic output ratio on the optimal decisions and expected profits of the green SC and its parties. With $\mu$ being the only variable, the change curves of the optimal decisions and expected profits with the changing mean of stochastic output ratio $\varepsilon$ are shown in Figure 3.
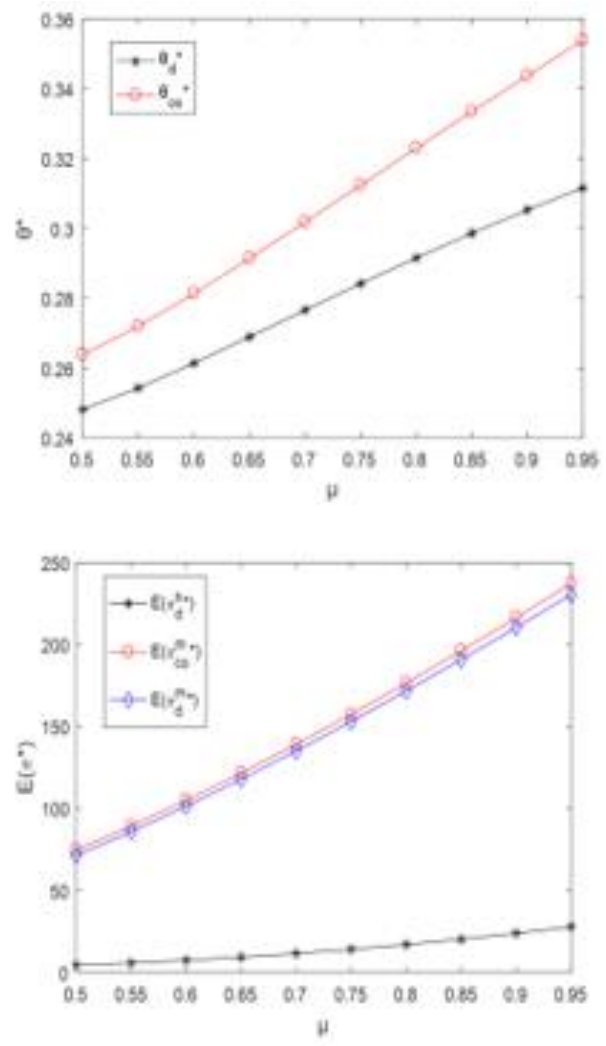

Figure 3. Effects of $\mu$ on the optimal decisions and expected profits of the green SC and its parties

As shown in Figure 3, with the growing mean of producer's expected output, the optimal AP greenness and optimal AP order quantity were both on the rise, so did the expected profits of the SC and both parties. However, the optimal wholesale price set by the producer was decreased. Compared with that under decentralized decision-making, the optimal decisions and expected profits of the green SC and its parties were sensitive to the changing $\mu$ value under the TPT contract. Therefore, the producer should increase the stochastic output of APs, in order to improve the environment and enhance the expected profits of the SC and its parties.

\subsection{Effects of the standard deviation of stochastic output ratio}

Finally, the author looked at the effects of the standard deviation of stochastic output ratio on the optimal decisions and expected profits of the green SC and its parties. With $\sigma$ being the only variable, the change curves of the optimal decisions and expected profits with the changing mean of stochastic output ratio $\varepsilon$ are shown in Figure 4.

As shown in Figure 4, with the growing standard deviation of producer's expected output, the optimal AP order quantity, the optimal AP greenness and the optimal wholesale price decreased across the board, so did the expected profits of the $\mathrm{SC}$ and the producer. The only increasing parameter is the seller's expected profit. It may seem counterintuitive that the seller's expected profit increased with the $\sigma$ (In common sense, output stochasticity must have a negative impact on the SC). However, this correlation can be derived from formula (11): the seller's expected profit decreases with the growth in $A$, and $A$ is negatively correlated with $\sigma$; thus, the seller's expected profit has a positive correlation with $\sigma$. Nevertheless, the SC profit decreased with the growing $\sigma$, for the increment of seller's expected profit is smaller than the decrement of producer's expected profit. 

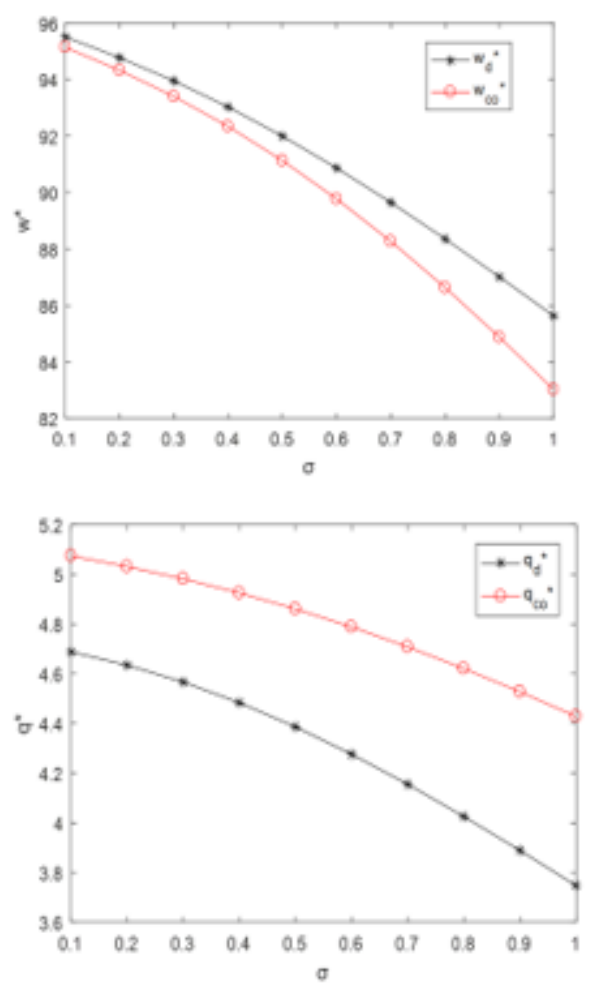
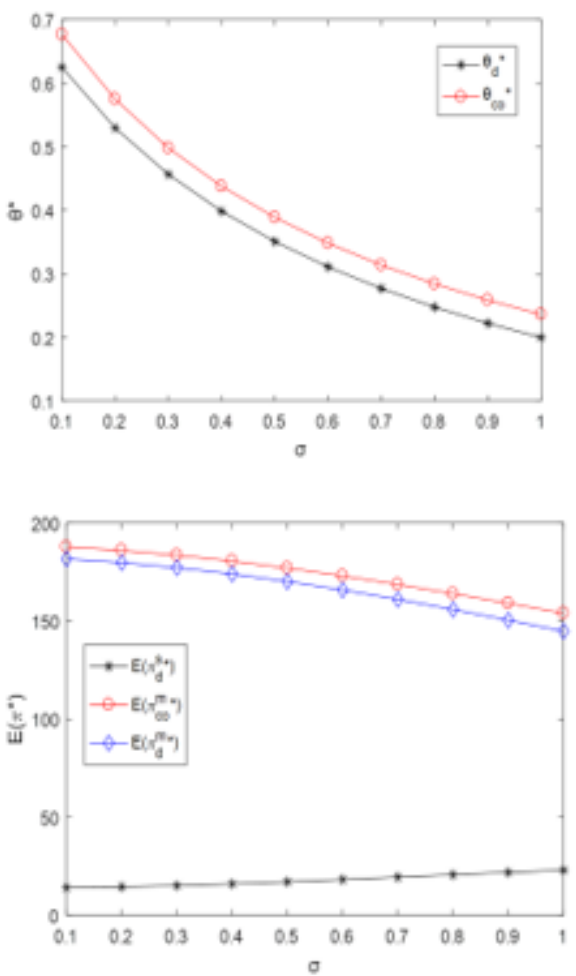

Figure 4. Effects of $\sigma$ on the optimal decisions and expected profits of the green SC and its parties

\section{CONCLUSIONS}

This paper explores the coordination of green AP SC with stochastic output. Two Stackelberg game models were established, respectively, under centralized and decentralized decision-making. Then, the green sensitivity, green cost coefficient and stochastic output ratio were subjected to sensitivity analysis, revealing how SC operations are affected by consumer's environmental awareness and stochastic demand. The main conclusions are as follows:

(1) If the consumer has a high awareness of environmental protection, he/she will be sensitive to AP greenness and willing to pay an extra fee for green APs. The growing environmental awareness of the consumer is an important market factor that promotes the SC environment. Thus, we should conduct green marketing to boost the consumer's awareness of environmental protection.

(2) If it is costly to develop green technologies, the producer will lower the AP greenness and wholesale price, while the seller will cut back on the AP order quantity. This means a high green cost coefficient is unfavorable to the environment. As a result, we should invest more in green technologies and reduce the R\&D cost of green APs.

(3) The increase in the mean of stochastic demand has positive effects on the $\mathrm{SC}$ profit and environment, while the increase in the standard deviation of stochastic demand has negative impacts on the latter factors. It may seem counterintuitive that the seller's expected profit increased with the $\sigma$. Nevertheless, the SC profit decreased with the growing $\sigma$, for the increment of seller's expected profit is smaller than the decrement of producer's expected profit.

(4) The cooperation between SC parties is necessary to improve the environmental performance of the SC. Under the TPT contract, the producer can cooperate fully with the seller, resulting in a coordinated $\mathrm{SC}$ and an improved environment.
However, only the producer can make more profits under this cooperation model. The seller's profit will remain the same as that under decentralized decision-making. The seller should be subsidized properly by the producer, such as to arouse its interests in adopting the TPT contract.

There are several limitations of our research. First, our models only consider an SC containing one type of APs. In future, the SC decision-making will be discussed under the competition between regular APs and green APs. Second, the author only took account of the producer's green investment, without considering the green marketing. The joint green marketing by the producer and the seller will be deliberated in further research. Third, the research problem was not explored from the angles of society or government. To improve the environment, the future research will further examine the effects of government subsidy on the performance of green AP SC.

\section{ACKNOWLEDGEMENTS}

The author gratefully acknowledges financial support from the Key Project of Humanities and Social Science Research in Colleges and Universities in Anhui Province (SK2018A0274) and the General Project of Foreign Visits and Training of Outstanding Young and Cadre Talents in Colleges and Universities (gxgwfx2018060) and the Key Project of the Doctoral Talent Funds of Fuyang Normal University (2017kyqd0006).

\section{REFERENCES}

[1] Wu, Z.H., Pagell, M. (2011). Balancing priorities: Decision-making in sustainable supply chain 
management. Journal of Operations Management, 29(6): 577-590. https://doi.org/10.1016/j.jom.2010.10.001

[2] Linton, J.D., Klassen, R., Jayaraman, V. (2007). Sustainable supply chains: An introduction. Journal of Operations Management, 25(6): 1075-1082. https://doi.org/10.1016/j.jom.2007.01.012

[3] Zhang, S.H., Wang, L. (2016). The coordination pricing game model of green agricultural product supply chain based on 3PL. Logistics Engineering and Management, 38(1): $\quad 77-80 . \quad$ https://doi.org/10.3969/j.issn.16744993.2016.01.030

[4] Liu, C.M., Hao, Q.S. (2018). Problems and countermeasures in the production and operation of green agricultural products under the background of "Internet +". Social Sciences in Yunnan, (6): 92-96.

[5] Srivastava, S.K. (2007). Green supply-chain management: A state-of-the-art literature review. International Journal of Management Reviews, 9(1): 5380. https://doi.org/10.1111/j.1468-2370.2007.00202.x

[6] Song, H.H., Gao, X.X. (2018). Green supply chain game model and analysis under revenue-sharing contract. Journal of Cleaner Production, 170: 183-192. https://doi.org/10.1016/j.jclepro.2017.09.138

[7] Hong, Z.F., Guo, X.L. (2019). Green product supply chain contracts considering environmental responsibilities. Omega, 83: 155-166. https://doi.org/10.1016/j.omega.2018.02.010

[8] Cao, Y., Li, Q.S., Hu, H.L. (2019). Research on the influence of different government subsidy strategies on the green decision-making of supply chain. Chinese Journal of Management, 16(2): 297-305. https://doi.org/10.3969/j.issn.1672-884x.2019.02.016

[9] Sarkis, J. (2003). A strategic decision framework for green supply chain management. Journal of Cleaner Production, 11(4): 397-409. http://dx.doi.org/10.1016/S0959-6526(02)00062-8

[10] Burer, S., Jones, P.C., Lowe, T.J. (2008). Coordinating the supply chain in the agricultural seed industry. European Journal of Operational Research, 185(1): 354377. http://dx.doi.org/10.1016/j.ejor.2006.12.015

[11] Liu, W.H., Liu, Y.P., Liu, B.L. (2010). The method and application of the closed reconstruction of green agricultural product supply chain. Soft Science, 24(4): 48-52. https://doi.org/10.3969/j.issn.10018409.2010.04.011

[12] Wang, C., Tang, M.P., Wang, L.L. (2013). Fresh produce supply chain decisions based on stackelberg game. Soft Science, 27(4): 99-105 https://doi.org/10.3969/j.issn.1001-8409.2013.04.020

[13] Ge, H.T., Gray, R., Nolan, J. (2015). Agricultural supply chain optimization and complexity: A comparison of analytic vs simulated solutions and policies. International Journal of Production Economics, 159: 208-220. http://dx.doi.org/10.1016/j.ijpe.2014.09.023

[14] Chen, H.F. (2017). Green agricultural product supply chain subject game under low carbon economy. Jiangsu Agricultural Sciences, 45(14): 293-296. https://doi.org/10.15889/j.issn.1002-1302.2017.14.074

[15] Yang, H.Z., Lu, G.D. (2018). Benefit coordination of fresh agricultural products three-level supply chain based on trade credit. Statistics \& Decision, 34(22): 51-55. https://doi.org/10.13546/j.cnki.tjyjc.2018.22.010

[16] Zhou, L.N., Zhou, G.G., Qi, F.Z., Cao, J. (2019).
Research on fresh agricultural supply chain network equilibrium with consumer's preference for organic product. Systems Engineering-Theory \& Practice, 39(2): 360-371. https://doi.org/10.12011/1000-6788-20170644-12

[17] Ling, L.Y., Guo, X.L., Hu, Z.J., Liang, L. (2013). The risk-sharing contracts under random yield and stochastic demand in agricultural supply chain. Chinese Journal of Management Science, 21(2): 50-57.

[18] Zhao, X., Wu, F.W. (2009). Coordination of agri-food chain with revenue-sharing contract under stochastic output and demand. Chinese Journal of Management Science, 17(5): 88-95.

[19] Kazaz, B., Webster, S. (2011). The impact of yielddependent trading costs on pricing and production planning under supply uncertainty. Manufacturing \& Service Operations Management, 13(3): 404-417. http://dx.doi.org/10.1287/msom.1110.0335

[20] Zhao, X., Wu, F.W., Cai, R. (2014). Research on coordination of two-stage supply chain under random yield and random demand with contracts. Journal of Management Sciences in China, 17(8): 34-47.

[21] Feng, Y., Yu, Y.L., Zhang, Y.Z., Wu, Q. (2017). Coordination of Agri-products supply chain with TPL's participation under random yield and random demand. Journal of Industrial Engineering and Engineering Management, 31(4): 156-163. https://doi.org/10.13587/j.cnki.jieem.2017.04.020

[22] Huang, J.H., Ye, F., Zhou, G.L. (2018). Decisions and the value of government compensation in agricultural supply chain under trade credit and uncertainty of production yield. Chinese Journal of Management Science, 26(1): 107-117. https://doi.org/10.16381/j.cnki.issn1003207x.2018.01.011

[23] Okyay, H.K., Karaesmen, F., Özekici, S. (2014). Newsvendor models with dependent random supply and demand. Optimization Letters, 8(3): 983-999. http://dx.doi.org/10.1007/s11590-013-0616-7

[24] Lan, C.F., Bi, G.B., Fei, Y.L. (2017). Supply chain with wholesale price contract under inequity aversion and random yield. Journal of University of Science and Technology of China, 47(6): 530-540. https://doi.org/10.3969/j.issn.0253-2778.2017.06.012

[25] Lan, C.F., Ji, H.Y., Li, J. (2015). A distribution-free newsvendor model with balking penalty and random yield. Journal of Industrial Engineering and Management, 8(3): 1051-1068. https://doi.org/10.3926/jiem.1365

[26] Boyabatli, O., Kleindorfer, P.R., Koontz, S.R. (2011). Integrating long-term and short-term contracting in beef supply chains. Management Science, 57(10): 1771-1787. https://doi.org/10.1287/mnsc. 1110.1362

[27] Liu, Z.L., Anderson, T.D., Cruz, J.M. (2012). Consumer environmental awareness and competition in two-stage supply chains. European Journal of Operational Research, 218(3): https://doi.org/10.1016/j.ejor.2011.11.027

[28] Agbo, M., Rousselière, D., Salanié, J. (2015). Agricultural marketing cooperatives with direct selling: A cooperative-non-cooperative game. Journal of Economic Behavior \& Organization, 109: 56-71. https://doi.org/10.1016/j.jebo.2014.11.003 